\title{
A Stress-strain Model Considering Bilinear and PostPeak Softening Behaviors for FRP-confined RC Columns
}

\author{
Zhenyu Wang* and Haytham F. Isleem \\ Harbin Institute of Technology, China; zhenyuwang@hit.edu.cn, haythamisleem@hit.edu.cn
}

\begin{abstract}
Objectives: A model with more generalized scope than those in the literature has been proposed to predict the stressstrain response of Fiber-Reinforced Polymer (FRP) confined rectangular RC columns under axial compression. Methods/ Statistical Analysis: 255 columns with their experimental data were used as a basis for the model expressions. Their database included columns with aspect ratios ranging from 1.0 to 2.0. Furthermore, the cross sectional depth varied from 100 to $500 \mathrm{~mm}$ and the unconfined concrete strength varied from 18.3 to $51.5 \mathrm{MPa}$. Findings: Based on interpretation of the test results, bilinear and post-peak softening stress-strain responses are proposed as referencing models, respectively, for columns having a sectional depth of smaller or larger than $300 \mathrm{~mm}$. The softening model is composed of a parabolic expression for describing the first stage of the response and two linear expressions for the second and third stages. The influences of aspect ratio and size of cross sections, number of FRP layers and internal hoop steel bars on the key features of the envelope stress-strain curve model (i.e. ultimate axial stress and strain) are all considered in the model. Application/ Improvements: Reasonable agreement was revealed between the analytical responses of the proposed model with the selected tested responses, confirming its ability to simulate the stress-strain behavior of FRP-confined rectangular RC columns of small or large sizes.
\end{abstract}

Keywords: FRP-confined Concrete, Rectangular RC Columns, Stress-strain Model

\section{Introduction}

The application of FRPs as confinement wraps has been extensively used to retrofit existing concrete columns in bridges and buildings. The significance of this subject is confirmed by a large number of investigations on circular specimens confined with FRP wraps and subjected to axial compression $\frac{1-3}{}$. Studies on FRP-confined unreinforced specimens of noncircular cross sections are also available ${ }^{4-6}$. Due to limited studies available for FRPconfined RC columns of non-circular cross-sections ${ }^{7-9}$, this paper provides a generalized model considering the effects of internal steel reinforcement and aspect ratio and size of cross-sections.
It is known that the columns in practice usually have internal steel reinforcement; however, the studies have not considered the internal steel reinforcement effect. Only few models were on FRP-confined RC columns under compressive axial loads $\frac{10,11}{}$ of these studies, a research to propose a model for the axial strength and strain capacities of RC columns with square and rectangular cross-sections confined with CFRP has been performed ${ }^{10}$. A series of 68 axial compressive tests on FRP-wrapped reinforced concrete in $150 \times 300 \mathrm{~mm}$ rectangular-sectioned and 250 $\times 250 \mathrm{~mm}$ square and circular-sectioned columns of 500 $\mathrm{mm}$ in height were conducted. The experiments on confined specimens revealed that the internal reinforcement bars contribute to the increase of their strength and duc-

${ }^{*}$ Author for correspondence 
tility. In the studies, the confinement pressure was due to the confinement by the FRP wraps and the steel hoops.

One of the key requirements for proposing a stressstrain model is the cross-sectional size and aspect ratio. Previous research works on FRP-wrapped columns have reported that the strength recorded at rupture of CFRP jacket decreases as the side-aspect ratio increases, and there is no significant improvement in the strength of large-sectioned columns (aspect ratio $=2.0$ ). The limitation of aspect ratio considered in the existing studies is within the range between 1 and 1.5. Of the recent studies on rectangular column sections, several column tests under compression loading to study the axial strength and stress-strain behavior of FRP-wrapped unreinforced concrete prisms have been conducted ${ }^{4}$. The sizes of test specimens were $120 \times 180 \times 300 \mathrm{~mm}$ (aspect ratio $=1.50)$ and $90 \times 180 \times 300 \mathrm{~mm}$ (aspect ratio $=2.0)$. Another experimental and theoretical works included axially-loaded unreinforced specimens of size $140 \times 180$ $\times 500 \mathrm{~mm}($ aspect ratio $=1.28)$ and $130 \times 200 \times 500 \mathrm{~mm}$ (aspect ratio $=1.54)$ to investigate and propose a model for their stress-strain response ${ }^{5}$. In reference to the studies recently introduced; the stress-strain test relationship of FRP-wrapped square columns of relatively larger size (i.e. $305 \times 305 \times 915 \mathrm{~mm}$ ) was different than that reported in the existing literature ${ }^{7}$. Furthermore, in a more recent study, 28 large scale RC columns of rectangular sections wrapped with CFRP were tested ${ }^{8}$. The experimental program included columns with $200 \times 300 \mathrm{~mm}$ (aspect ratio $=1.5)$ and $200 \times 400 \mathrm{~mm}$ (aspect ratio $=2.0)$ cross sections was considered to comprise an acceptable range of columns dimension and height (1000 $\mathrm{mm}$ for all specimens). The results showed that the confined specimens exhibited a post-peak softening behavior with little enhancement in axial stress. The lightly-confined specimens experienced reductions in their ultimate strengths. Due to the effects of column section size and its aspect ratio, the decrease in rupture strength was more significant for the $200 \times 400 \times$ $1000 \mathrm{~mm}$ (aspect ratio $=2.0$ ) columns compared to the $150 \times 300 \times 1000 \mathrm{~mm}($ aspect ratio $=1.5)$ columns.

Most existing models on the axial compressive response of concrete with external FRP confinement have focused on unreinforced concrete specimens of smallscale, and the proposed models are based on bilinear stress-strain test results (Figure 1). To the best knowledge of the writers, the influence of column size and internal reinforcement have been only considered for
CFRP-confined square RC columns of medium $204 \times 204$ $\times 612 \mathrm{~mm}$ and large $305 \times 305 \times 915 \mathrm{~mm}^{2}$ sizes $^{\mathrm{T}}$. Results of their tests revealed the confinement by the CFRP slightly enhanced the strength of specimens and resulted in either bilinear or a post-peak softening behavior. This behavior was based on the amount of confinement which was significantly influenced by the sectional size. Moreover, the internal hoop reinforcement has also an impact on the stress-strain shape response by enhancing the axial strain. No model that considers bilinear and post-peak softening responses was also reported earlier for FRPconfined rectangular reinforced concrete sections. This paper, therefore, provides a modified confinement pressure model that incorporates all these effects to give accurate predictions for the strength of rectangular RC columns with external FRP confinement. In the model, the influences of column section size and its aspect ratio on the strength and ductility results, effective rupture FRP strain and internal hoop reinforcement were carefully accounted for. The rectangular sections modeled in this research included columns with a sectional aspect ratio ranging from 1.0 to 2.0. First, the lateral pressure by the FRP wraps for columns exhibited bilinear and post-peak softening behaviors was determined. A generalized model was then applied to describe the stress-strain curve components of FRP-confined columns with different section sizes. Finally, the assessment of the model components was done against selected test responses available in the technical literature.

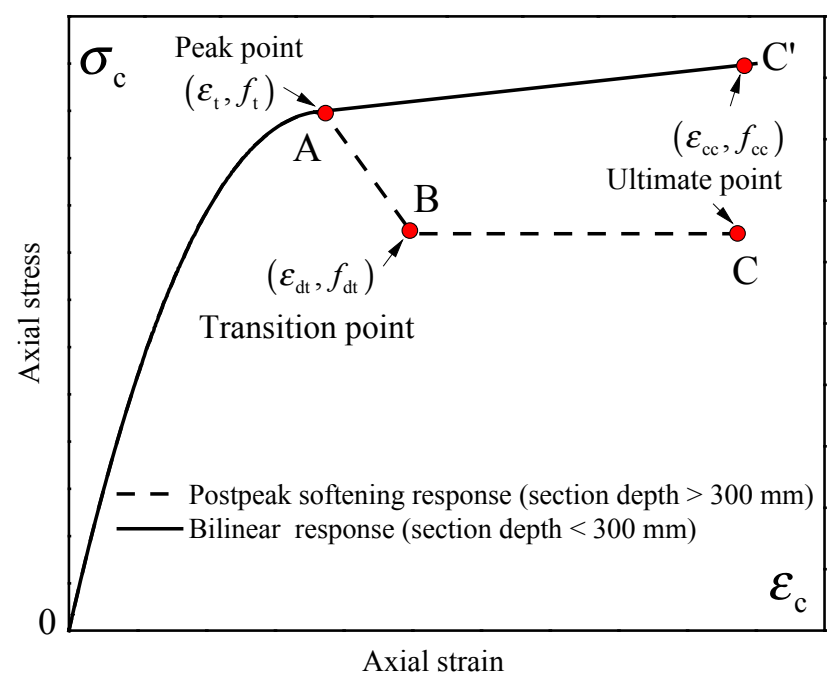

Figure 1. Stress-strain relationships of small and large-sized FRP-wrapped columns. 


\section{Test Database}

To develop an axial stress-strain model and also to check the accuracy of this model, a set of 255 tested specimens with different material properties and geometries were as a basis for most of the regressed expressions provided in this paper. In reference to the reviewed literature, a large number of experimental tests were conducted on FRPwrapped specimens of square and rectangular sections. In recent years, a confinement strength model based on extensive test data accumulated from the existing literature has been provided ${ }^{9}$. A selection of these results is also adopted in this paper to propose the expressions required for a complete stress-strain model.

To account for the effects of an acceptable range of test factors on the effectiveness of FRP, for the unconfined concrete cylinder the strength ranged from 10.8 MPa to $51.5 \mathrm{MPa}$ and the cross-sectional areas ranged from 100 $\mathrm{cm}^{2}$ to $1600 \mathrm{~cm}^{2}$. The rectangular section side ranged from $100 \mathrm{~mm}$ to $500 \mathrm{~mm}$ and its sectional aspect ratio from 1 to 2.0 , among them $(h / b=1 ; 148$ specimens $),(h / b=1.253$; 6 specimens), $(h / b=1.286 ; 3$ specimens $),(h / b=1.5 ; 28$ specimens), $(h / b=1.533 ; 6$ specimens $),(h / b=1.538 ; 3$ specimens), $(h / b=1.725 ; 12$ specimens $),(h / b=1.753 ; 6$ specimens), and ( $h / b=2.0 ; 43$ specimens). Furthermore, the strength of FRP wraps under tensile tests varied from 780 to $4519 \mathrm{MPa}$, its elastic modulus of from 60 to 257 $\mathrm{GPa}$, and the thickness of one FRP sheet of from $0.13 \mathrm{~mm}$ to $1.2 \mathrm{~mm}$. Complete details about the compiled experiments are not provided in this current paper; however, the readers are directed to their cited papers.

\section{Overview of Stress-strain Test Responses}

As mentioned before, tests on the influences of hoop steel reinforcement and section size on the behavior of square columns of medium and large sizes (respectively as 204 $\times 204 \times 612 \mathrm{~mm}$ and $305 \times 305 \times 915 \mathrm{~mm}$ ) wrapped with FRP have been conducted ${ }^{7}$. As it was concluded in their studies, the confinement from the CFRP slightly increased the strength capacity and the confined specimens exhibited bilinear and post-peak softening behavior (Figure 1), which were based on the column section size. The internal steel reinforcement significantly influenced the stress-strain test results. An axial compression model for the stress-strain curve response of FRP-wrapped spec- imens of rectangular sections $(160 \times 160 \mathrm{~mm}, 140 \times 180$ $\mathrm{mm}$, and $130 \times 200 \mathrm{~mm}$ ) and a height of $500 \mathrm{~mm}$ has been developed 5 . The curve model was bilinear response with ascending or descending second component depending on the confinement level and the shape and column section size. It has been confirmed that, independently of the FRP confinement level, the section's size affects the stressstrain response branches ${ }^{8}$.

In this subsection the bilinear and post-peak softening stress-strain responses drawn in Figure 1 are used herein as referencing models for columns with $(h<300$ ) and columns with ( $h>300)$. As shown, the post-peak softening model consists of three distinct curves, namely (1) A polynomial ascending curve (OA), which describes the first stage of the response, initiates from the beginning point at which $\left(\sigma_{\mathrm{c}}=0, \varepsilon_{\mathrm{c}}=0\right)$ and extends to the peak point when the confined concrete reaches their peak strength and strain, which are denoted as $\left(\sigma_{\mathrm{c}}=\sigma_{\mathrm{t}}\right.$ , $\varepsilon_{\mathrm{c}}=\varepsilon_{\mathrm{t}}$ ), (2) The second stress-strain curve segment $(\mathrm{AB})$ is a descending curve extending from the peak to the transitional stress points $\left(\sigma_{\mathrm{c}}=\sigma_{\mathrm{dt}}, \varepsilon_{\mathrm{c}}=\varepsilon_{\mathrm{dt}}\right)$, and finally (3) The portion (BC) extends from the transition stress to the point which represents the ultimate condition of confined columns were the FRP ruptures at a point denoted as $\left(\sigma_{\mathrm{c}}=\sigma_{\mathrm{cc}}, \varepsilon_{\mathrm{c}}=\varepsilon_{\mathrm{cc}}\right)$. The bilinear response model consists of two branches: (1) an ascending first branch $(\mathrm{OA})$ and (2) a linear second branch (AC').

\section{Analytical Modeling}

\subsection{Effective Lateral Pressure by FRP}

The lateral stress from the FRP confinement is estimated by the following widely-known formula ${ }^{12}$.

$$
f_{l f}=k_{e f} \frac{2 E_{f} n t_{f} \varepsilon_{f e}}{D}=0.5 k_{e f} \rho_{f} E_{f} k_{\varepsilon} \varepsilon_{f u}
$$

where, $E_{\mathrm{f}}=$ elastic modulus of FRP (MPa); $n=$ number of FRP-wrapped layers; $t_{\mathrm{f}}=$ thickness of single layer of FRP $(\mathrm{mm}) ; \varepsilon_{\mathrm{fu}}$ (from coupon tensile tests $)=$ FRP strain at rupture; $\rho_{\mathrm{f}}=4 n t_{f} / D=$ ratio of FRP layers, in which 
$D=\sqrt{b^{2}+h^{2}}=$ equivalent diameter of rectangular section column; the shape factor (Eq. 2) accounts for noncircular section having rounded corners (Figure 2 (a)), given as $k_{\mathrm{ef}}=A_{\mathrm{e}} / A_{\mathrm{cc}}$.

$k_{\mathrm{ef}}=\frac{A_{\mathrm{c}}}{A_{\mathrm{cc}}}=\frac{1-\left((h / b)\left(b-2 r_{\mathrm{c}}\right)^{2}+(b / h)\left(h-2 r_{\mathrm{c}}\right)^{2} /\left(3 A_{\mathrm{g}}\right)\right)-\rho_{\mathrm{sc}}}{1-\rho_{\mathrm{sc}}}$

where, $r_{\mathrm{c}}(\mathrm{mm})=$ radius of edges of FRP-wrapped rectangular section; $\rho_{\mathrm{sc}}=$ vertical reinforcement ratio; $A_{\mathrm{g}}\left(\mathrm{mm}^{2}\right)=$ area of a rectangular section column having rounded corners (Eq. (3)).

$$
A_{\mathrm{g}}=b h-\left((4-\pi) r_{\mathrm{c}}^{2}\right)
$$

The FRP rupture strain at the section corners decreases as the section size increases ${ }^{8.9}$. An effective rupture strain $\varepsilon_{\mathrm{fe}}$ which depends on the section size is hence incorporated in the model. The fe value was obtained from Eq. (4) reported in recent literature $\frac{8,9}{9}$.

$$
k_{\mathrm{a}}=\frac{\mathrm{fe}}{\mathrm{fu}}=1-0.38\left(\frac{}{100}\right)^{0.41} \text { for } 100 \leq b \leq 400 \mathrm{~mm}
$$

where, $b(\mathrm{~mm})=$ width of a square section $(\mathrm{mm})$. For a rectangular section, $b$ is replaced by the section's depth, $h$.

The effective lateral pressure provided by the internal hoop reinforcement is calculated by the following expression as done by the researchers $\frac{13}{}$.

$$
f_{\mathrm{ls}}=k_{\mathrm{e}} \rho_{\mathrm{eff}} f_{\mathrm{yt}}
$$

where, $f_{\mathrm{yt}}=$ yield strength of hoop steel reinforcement $(\mathrm{MPa}) ; \rho_{\text {eff }}=$ effective hoop reinforcement ratio calculated by Eq. (6) $)^{11}$.

$$
\rho_{\text {eff }}=\frac{\frac{A_{\text {shx }}}{s c_{\mathrm{y}}} c_{\mathrm{x}}+\frac{A_{\text {shy }}}{s c_{\mathrm{x}}} c_{\mathrm{y}}}{c_{\mathrm{x}}+c_{\mathrm{y}}}
$$

where, $A_{\text {shx }}$ and $A_{\text {shy }}\left(\mathrm{mm}^{2}\right)=$ the total sectional areas of the hoop bars along the width and depth sides of a rectangular section (Figure $2(\mathrm{~b})$ ); $c_{\mathrm{x}}$ and $c_{\mathrm{y}}=$ center-line distances between the hoop legs along the section sides (mm), respectively; in Eq. (7), the $k_{\text {es }}$ and $k_{\mathrm{v}}$ are for the steel-confinement effectiveness ${ }^{\underline{14}}$.

$k_{\mathrm{e}}=k_{\mathrm{es}} k_{\mathrm{v}}=\frac{1-\sum\left(w_{\mathrm{xi}}^{2}+w_{\mathrm{yi}}^{2}\right) / 6 x y}{1-\rho_{\mathrm{cc}}}\left(1-\frac{s^{\prime}}{2 x}\right)\left(1-\frac{s^{\prime}}{2 y}\right)$

where, $w_{\mathrm{xi}}$ and $w_{\mathrm{yi}}(\mathrm{mm})=$ internal clear distances between longitudinal bars along the $x$ - and $y$ of a rectangular section; $x$ and $y(\mathrm{~mm})=$ dimensions to the centerline of steel hoops $(\mathrm{mm}) ; s^{\prime}(\mathrm{mm})=$ clear spacing between hoops in vertical direction; $\rho_{\mathrm{cc}}=$ ratio of vertical reinforcement area to area of concrete core.

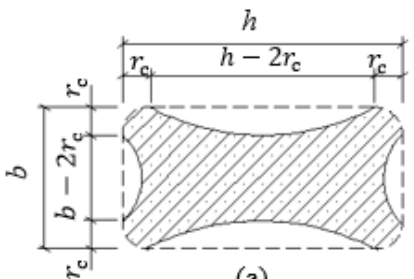

(a)

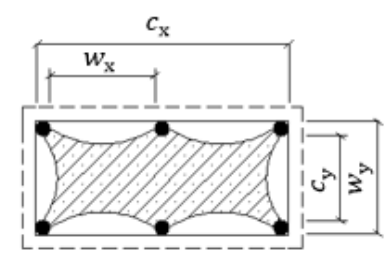

(b)
Figure 2. Confinement provided by FRP and steel hoops to concrete.

\subsection{Peak Axial Stress, $\sigma_{\mathrm{t}}$, and Axial Strain, $\varepsilon_{\mathrm{t}}$}

The peak condition of FRP-wrapped concrete $\left(\sigma_{t}, \varepsilon_{t}\right)$ is an important parameter for a stress-strain model. Based on a multi-parameter regression analysis of the previously cited experiments, the following expression considering the contribution of internal steel reinforcement and CFRP parameters is, thus, proposed, in which the correlation coefficient $\left(R^{2}\right)$ is $95 \%$.

$\sigma_{\mathrm{t}} / f_{\mathrm{c}}^{\prime}=\left(0.91+0.232 \frac{k_{\mathrm{ef}} \rho_{\mathrm{f}} f_{\mathrm{f}}}{f_{\mathrm{c}}^{\prime}}+1.261 \frac{\rho_{\mathrm{eff}} f_{\mathrm{yt}}}{f_{\mathrm{c}}^{\prime}}+0.985 \frac{\rho_{\mathrm{sc}} f_{\mathrm{yl}}}{f_{\mathrm{c}}^{\prime}}\right)$

In this equation, $f_{\mathrm{yt}}$ and $f_{\mathrm{yl}}(\mathrm{MPa})=$ yield strengths of the internal hoop and longitudinal bars, respectively; $f_{\mathrm{f}}(\mathrm{MPa})=$ ultimate strength of FRP under tensile tests.

As for the corresponding peak strain, the interpretation of results reveals that the influence of the longitudinal reinforcing steel bars on this strain is almost negligible ${ }^{7}$. However, the peak strain is found to be influenced by the lateral confinement provided by the CFRP wrap and hoop reinforcement. As a result, Eq. (9) for calculating 
the parameter $\varepsilon_{\mathrm{t}}$ is proposed, in which the correlation coefficient $\left(R^{2}\right)$ is approximately $91 \%$.

$\varepsilon_{\mathrm{t}}=\varepsilon_{\mathrm{co}}\left(1+3.55\left(\frac{k_{\mathrm{ef}} \rho_{\mathrm{f}} f_{\mathrm{f}}}{f_{\mathrm{c}}^{\prime}}\right)^{2.242}+7.84\left(\frac{\rho_{\text {eff }} f_{\mathrm{yt}}}{f_{\mathrm{c}}^{\prime}}\right)^{0.843}\right)$

where, $\varepsilon_{\mathrm{co}}=$ axial strain at peak condition for uncon-

fined concrete, assumed as 0.002 .

\subsection{Ultimate Axial Stress, $\sigma_{\mathrm{cc}}$, and Axial}

Strain, $\varepsilon_{\mathrm{cc}}$

The ultimate stress, $\sigma_{\mathrm{cc}}$, and corresponding axial strain, $\varepsilon_{\mathrm{cc}}$, are the most important parameters for defining a complete axial stress-strain response of confined concrete. Based on a multi-parameter regression analysis of selected test results, the two expressions for estimating the effective strength confinement are therefore proposed in which the correlation coefficient $R^{2}$ is $90.0 \%$ (as shown in Figure 3). Briefly, the proposed confinement model is summarized by the following steps: (1) The FRP strain efficiency factor $\left(k_{\mathrm{a}}\right)$ is estimated using Eq. (4); (2) the effective lateral pressure from the FRP $\left(f_{\text {lf }}\right)$ is found by Eqs. (1-3); (3) the effective pressure from the hoop reinforcement is by Eqs. (5-7); (4) the modified confinement pressure ratio $M C_{\mathrm{R}}$ is by Eq. (11), and as a result (5) the strength at ultimate loading of rectangular column with FRP wraps $\left(\sigma_{\mathrm{cc}}\right)$ is by

$$
\begin{gathered}
\sigma_{\mathrm{cc}} / f_{\mathrm{c}}^{\prime}=0.64+3.93 M C_{\mathrm{R}} \\
M C_{\mathrm{R}}=2.17\left(\frac{b}{h}\right)^{0.24}\left(\frac{f_{\mathrm{lf}}}{f_{\mathrm{c}}^{\prime}}\right)^{1.10}+0.12\left(\frac{f_{\mathrm{ls}}}{f_{\mathrm{c}}^{\prime}}\right)^{0.10}
\end{gathered}
$$

As for the ultimate strain $\varepsilon_{\mathrm{cc}}$, Eq. (12) with an $\left(R^{2}\right)$ value of 0.8 was calibrated based on a selected test database of small and large scale column tests $\frac{7.8}{}$.

$$
\varepsilon_{\mathrm{cc}}=0.002\left[2.0+\left(50.7 \frac{h}{b} \frac{f_{\mathrm{lf}}}{f_{\mathrm{c}}^{\prime}}\right)+\left(35.0 \frac{f_{\mathrm{ls}}}{f_{\mathrm{c}}^{\prime}}\right)\right]
$$

\subsection{Transition Stress, $\sigma_{\mathrm{dt}}$ and Strain $\varepsilon_{\mathrm{dt}}$}

The descending branch of a post-peak softening stressstrain response was found to be controlled by the hoop steel reinforcement ratio, number of FRP layers, and aspect ratio of a rectangular-sectioned column. An analysis was performed on selected test data to propose the following expressions of $\sigma_{\mathrm{dt}}$ and $\varepsilon_{\mathrm{dt}}$.

$$
\sigma_{\mathrm{dt}}=0.00033\left(\frac{b}{h}\right)^{0.717} \sigma_{\mathrm{t}}^{3.06}
$$

$$
\varepsilon_{\mathrm{dt}}=11.57\left(\frac{h}{b}\right)^{0.53} \varepsilon_{\mathrm{t}}^{1.38}
$$

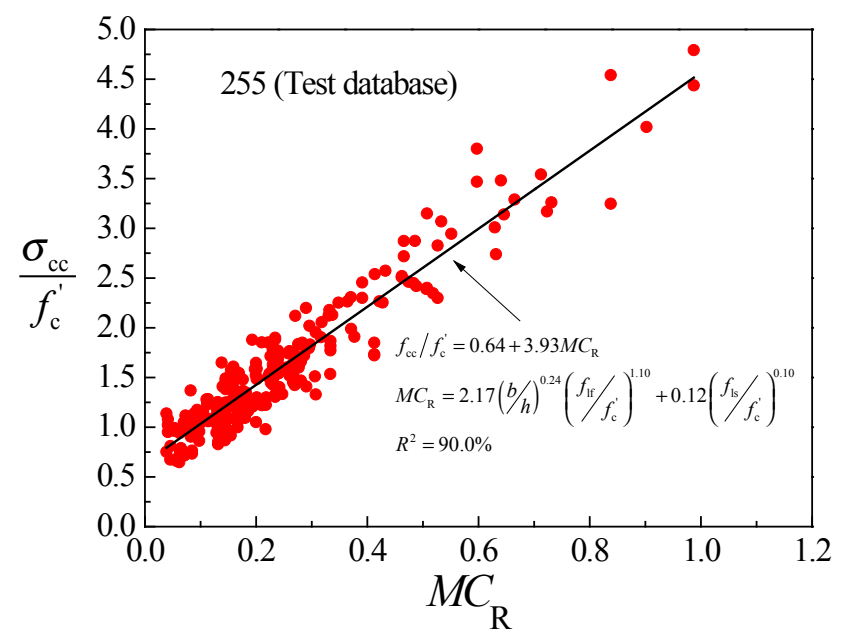

Figure 3. Strength enhancement ratio $\frac{\sigma_{\mathrm{cc}}}{f_{\mathrm{c}}^{\prime}}$ versus effective confinement pressure ratio $M C_{\mathrm{R}}$.

\subsection{Complete Stress-strain Model}

The stress-strain response can be predicted using the important features of the curve (points A, B, C and C' (Figure 1). The expressions for describing the three portions of the post-peak softening are provided in Eq. (15). The expressions for the bilinear response are provided in Eq. (16), which are similar to those provided in many existing studies.

$\begin{cases}\sigma_{\mathrm{c}}=\sigma_{\mathrm{t}}\left[A\left(\frac{\varepsilon_{\mathrm{c}}}{\varepsilon_{\mathrm{t}}}\right)+(3-2 A)\left(\frac{\varepsilon_{\mathrm{c}}}{\varepsilon_{\mathrm{t}}}\right)^{2}+(A-2)\left(\frac{\varepsilon_{\mathrm{c}}}{\varepsilon_{\mathrm{t}}}\right)^{3}\right] & \varepsilon_{\mathrm{c}} \leq \varepsilon_{\mathrm{t}} \\ \sigma_{\mathrm{c}}=\sigma_{\mathrm{t}}+E_{11}\left(\varepsilon_{\mathrm{c}}-\varepsilon_{\mathrm{t}}\right) & \varepsilon_{\mathrm{t}} \leq \varepsilon_{\mathrm{c}} \leq \varepsilon_{\mathrm{dt}} \\ \sigma_{\mathrm{c}}=\sigma_{\mathrm{dt}}+E_{21}\left(\varepsilon_{\mathrm{c}}-\varepsilon_{\mathrm{dt}}\right) & \varepsilon_{\mathrm{dt}} \leq \varepsilon_{\mathrm{c}} \leq \varepsilon_{\mathrm{cc}}\end{cases}$

$\left\{\begin{array}{lc}\sigma_{\mathrm{c}}=\sigma_{\mathrm{t}}\left[A\left(\frac{\varepsilon_{\mathrm{c}}}{\varepsilon_{\mathrm{t}}}\right)+(3-2 A)\left(\frac{\varepsilon_{\mathrm{c}}}{\varepsilon_{\mathrm{t}}}\right)^{2}+(A-2)\left(\frac{\varepsilon_{\mathrm{c}}}{\varepsilon_{\mathrm{t}}}\right)^{3}\right] & \varepsilon_{\mathrm{c}} \leq \varepsilon_{\mathrm{t}} \\ \sigma_{\mathrm{c}}=\sigma_{\mathrm{t}}+E_{22}\left(\varepsilon_{\mathrm{c}}-\varepsilon_{\mathrm{t}}\right) & \varepsilon_{\mathrm{t}} \leq \varepsilon_{\mathrm{c}} \leq \varepsilon_{\mathrm{cc}}\end{array}\right.$ 


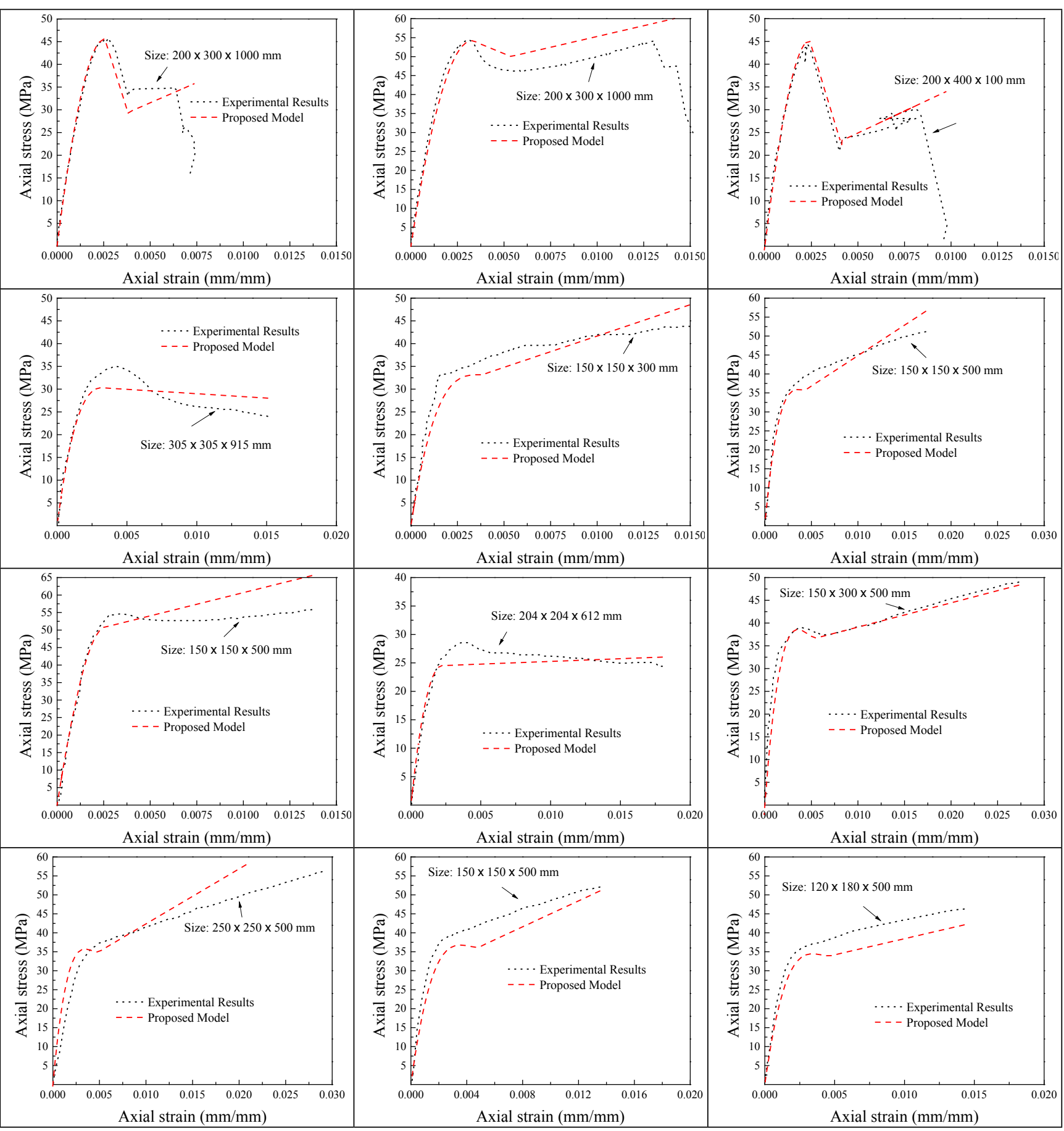

Figure 4. Comparison of predicted stress-strain results with existing test relationships for FRP-wrapped columns.

$$
\left\{\begin{array}{l}
E_{11}=\frac{\sigma_{\mathrm{dt}}-\sigma_{\mathrm{t}}}{\varepsilon_{\mathrm{dt}}-\varepsilon_{\mathrm{t}}} \\
E_{21}=\frac{\sigma_{\mathrm{cc}}-\sigma_{\mathrm{dt}}}{\varepsilon_{\mathrm{cc}}-\varepsilon_{\mathrm{dt}}} \\
E_{22}=\frac{\sigma_{\mathrm{cc}}-\sigma_{\mathrm{t}}}{\varepsilon_{\mathrm{cc}}-\varepsilon_{\mathrm{t}}}
\end{array}\right.
$$

where, is $E_{11}$ is the slope of the second segment of softening stress-strain response, whereas $E_{21}$ is its third segment's slope; $E_{22}$ is the slope of the second portion of the two branch response; the $A$ can be obtained as $A=E_{\mathrm{c}} / E_{\mathrm{p}}$, in which $E_{\mathrm{c}}=4733 \sqrt{f_{\mathrm{c}}^{\prime}}(\mathrm{MPa})=\operatorname{modu}-$ 
lus of elasticity ${ }^{15} ; E_{\mathrm{p}}=\sigma_{\mathrm{t}} / \varepsilon_{\mathrm{t}}(\mathrm{MPa})=$ second modulus at peak point (Point (A) described in Figure 2).

\subsection{Evaluation of the New Model}

In Figure 4, the accuracy of the proposed components of the stress-strain model is also verified by comparing its predictions with results selected from the relevant studies ${ }^{16}$. The comparisons of the model responses with the selected stress-strain results of confined columns of differences section sizes demonstrate that the model can also describe the stress-strain curve shapes.

\section{Acknowledgement}

The second author greatly appreciates the financial support from the China Scholarship Council for the doctoral study conducted in China.

\section{Conclusions}

In this work, a new model with several proposed expressions to predict the stress-strain response of columns reinforced with internal steel hoops and wrapped with FRP is provided. The proposed model characteristics are: (1) it takes into account the influences of several major parameters, namely, (1) section size, (2) aspect ratio, (3) internal hoop reinforcement, (4) effective FRP hoop strain at rupture, and (5) corner radius; (2) it considers bilinear and post-peak softening responses. Close agreement was reported between the responses of the proposed model with the compiled test data, confirming its ability to simulate the axial stress-strain behavior of rectangular RC columns with external FRP confinement. More experiments considering different ranges of sectional area and confinement level for columns with different FRP materials and concrete properties is necessary to examine the model performance.

\section{References}

1. Micelli F, Modarelli R. Experimental and analytical study on properties affecting the behavior of FRP-confined concrete. Composites: Part B-Engineering. 2013; 45:1420-31. https://doi.org/10.1016/j.compositesb.2012.09.055

2. Cascardi A, Micelli F, Aiello MA. Unified model for hollow columns externally confined by FRP. Engineering
Structures. 2016; 111:119-30. https://doi.org/10.1016/j. engstruct.2015.12.032

3. Zeng JJ, Guo YC, Gao WY, Li JZ, Xie JH. Behavior of partially and fully FRP-confined circularized square columns under axial compression. Construction and Building Materials. 2017; 152:319-32. https://doi.org/10.1016/j.conbuildmat.2017.06.152

4. Abbasnia R, Hosseinpour F, Rostamian M, Ziaadiny $\mathrm{H}$. Cyclic and monotonic behavior of FRP confined concrete rectangular prisms with different aspect ratios. Construction and Building Materials. 2013; 40:118-25. https://doi.org/10.1016/j.conbuildmat.2012.10.008

5. Hany NF, Hantouche EG, Harajli MH. Axial stress-strain model of CFRP-confined concrete under monotonic and cyclic loading. Journal of Composites for Construction. 2015; 19(6). https://doi.org/10.1061/(ASCE)CC.19435614.0000557

6. Abbasnia R, Ziaadiny H. Experimental investigation and strength modeling of CFRP-confined concrete rectangular prisms under axial monotonic compression. Materials and Structures. 2015; 48:485-500. https://doi.org/10.1617/ s11527-013-0198-y

7. Wang ZY, Wang DY, Smith ST, Lu DG. CFRP-confined square RC columns. I: Experimental investigation. Journal of Composites for Construction. 2012; 16(2):150-60. https://doi.org/10.1061/(ASCE)CC.1943-5614.0000245

8. Isleem HF, Wang ZY, Wang DY, Smith ST. Monotonic and cyclic axial compressive behavior of CFRP-confined rectangular RC columns. Journal of Composites for Construction. 2018; 22(4). https://doi.org/10.1061/(ASCE)CC.19435614.0000860

9. Isleem HF, Wang DY, Wang ZY. A new numerical model for polymer-confined rectangular concrete columns. Proceedings of the Institution of Civil Engineers: Structures and Buildings. 2018; 70(20):1064-79.

10. Ilki A, Peker O, Karamuk E, Demir C, Kumbasar N. FRP retrofit of low and medium strength circular and rectangular reinforced concrete columns. Journal of Materials in Civil Engineering. 2008; 20(2):169-88. https://doi.org/10.1061/(ASCE)0899-1561(2008)20:2(169)

11. Luca DA, Nardone F, Matta F, Nanni A, Lignola GP, Prota A. Structural evaluation of full-scale FRP-confined reinforced concrete columns. Journal of Composites for Construction. 2011; 15(1):112-23. https://doi.org/10.1061/ (ASCE)CC.1943-5614.0000152

12. Guide for the design and construction of externally bonded FRP systems for strengthening concrete structures. American Concrete Institute, ACI-440.2R-08. Farmington Hills, MI, USA; 2008.

13. Isleem HF, Wang DY, Wang ZY. Axial stress-strain model for square concrete columns internally confined with GFRP 
hoops. Magazine of Concrete Research. 2018; 70(20):106479. https://doi.org/10.1680/jmacr.17.00122

14. Sheikh SA, Uzumeri SM. Analytical model for concrete confinement in tied columns. Journal of the Structural Division. 1982; 108(12):2703-22.

15. Building code requirements for structural concrete and commentary. American Concrete Institute (ACI), ACI 31802. Farmington Hills, MI, USA; 2002. p. 1-438.
16. Ilki A, Kumbasar N. Compressive behaviour of carbon fiber composite jacketed concrete with circular and non-circular cross-sections. Journal of Earthquake Engineering. 2007; 7(3):381-406. https://doi.org/10.1080/13632460309350455 